\title{
Technological and Characteristics of Low-Fat Cheeses: A Review
}

\section{Hammam, A.R.A. ${ }^{1,2}$ and M.S.I. Ahmed ${ }^{2}$}

${ }^{1}$ Dairy and Food Science Department, South Dakota State University, Brookings 57007, SD, USA

${ }^{2}$ Dairy Science Department, Faculty of Agriculture, Assiut University, Assiut, Egypt

Received on: 6/3/2019 Accepted for publication on: 19/3/2019

\begin{abstract}
Cheese is a dairy-product and obtained from milk by using starter cultures and enzymes to coagulate the milk through a chemical process. Cheese has one of the highest growth rates among dairy products manufactured in many countries. Cheese could be divided into two major categories based on the fat content, including full-fat cheese and reduced or low-fat cheese. The low-fat cheese term differs within cheese varieties, countries, and other factors. Generally, cheese with fat content less than the full-fat version is considered low-fat cheese for consumers. The consumption and marketing of low-fat cheeses have accelerated over the last two decades. Fat is important due to its major contribution to the flavor, body and texture of the cheese. Numerous low-fat cheeses are characterized as mild flavor, weak body and texture, and less functional characteristics. Intensive research on low-fat cheese has developed three basic strategies for addressing fat-related problems, such as modifications of procedures, adjunct cultures, and fat replacers. This work aim is to highlight and review the characteristics of two types of low-fat cheeses, such as low-fat process cheese (LFPC) and low-fat Cheddar cheese (LFCC).
\end{abstract}

Keywords: Low-fat cheese, low-fat process cheese, low-fat Cheddar cheese, cheese sensory, cheese functionality

\section{Introduction}

When the term "reduced fat", "reduced in fat", "fat reduced", "less fat", "lower fat", or "lower in fat" is used on the products label, it means the product or food must contain at least $25 \%$ less fat than the reference amount in the traditional standardized cheese (FDA, 2014). This fat amount is slightly different in other countries due to the differences in the regulations.

The production and consumption of low-fat cheeses have elevated in the last two decades. As a result, many investigations have been conducted on study the characteristics of low-fat cheeses (Bellisle et al., 1994; Gould et al., 1994; Solheim and
Lawless, 1996; Ryhänen et al., 2001; Banks, 2004; Sánchez-Macías et al., 2010; Wadhwani and McMahon, 2012; Rashidinejad et al., 2013) to improve their characteristics as compared to full-fat cheeses.

Several methods have been studied to enhance the characteristics of low-fat cheeses, some of which include moisture control, starter selection, removal of calcium, and control of amounts of lactic acid in cheese (Chen et al., 1991; Merrill et al., 1994; Nauth and Hayashi, 1995). Increasing the moisture of low-fat cheeses is a common approach to enhance the body and texture of these types of cheese. Even though there were improvements in the quality of 
cheese with these approaches, the low-fat cheeses were still not similar to whole-fat cheeses.

Decreasing the fat has a major impact on the organoleptic characteristics of the cheese. It results in a body and texture that is hard and rubbery and lacks pliable characteristics of that specific variety of cheese (Mistry, 2001; Banks, 2004; Johnson et al., 2009; McMahon, 2010). It also affects the flavor of cheese adversely (Brown, 1989; Mistry and Anderson, 1993; Metzger and Mistry, 1994; Mistry, 1995).

\section{Process cheese (PC)}

Process cheese (PC) is a dairy food prepared by blending and heating various dairy and non-dairy ingredients to produce a pasteurized product with an extended shelf-life (Meyer, 1973; Thomas, 1973; Kapoor and Metzger, 2008). There is a unique microstructure in $\mathrm{PC}$ which renders a variety of functional characteristics (Kapoor and Metzger, 2008). Adding emulsifying salts, such as sodium citrate and sodium phosphate improves the emulsification properties of casein in natural cheese by displacing the calcium phosphate complexes that are present in the insoluble calcium-paracaseinatephosphate network in natural cheese
(Gupta et al., 1984; Caric et al., 1985; Berger et al., 1998; Kapoor and Metzger, 2008), which results in the disruption of the natural cheese protein network and exposure of hydrophilic and hydrophobic portions of the casein. Additionally, the hydrophilic interact with the aquatic portion while hydrophobic interact with the fat portion when shear and heat are applied (Marchesseau and Cuq, 1995; Ennis et al., 1998; Lee et al., 2003) to form a uniform closely knit protein network.

\section{1. Low-fat PC}

The chemical composition of whole or full-fat and low-fat PC is presented in Figure 1. The major source of fat in PC is natural cheese and it contributes more than $90 \%$ of the total fat in PC. Other dairy ingredients such as butter oil, butter, and dried cream contribute the remaining fat in a typical PC formulation. As a result, in order to manufacture a lowfat PC, utilization of a lower-fat or fat-free natural cheese is important. Previous studies on the manufacture of low-fat PC using low-fat natural cheese concluded that many functional and sensory defects that are associated with the use of low/fat-free fat natural cheese (Muir et al., 1997; Gwartney et al., 2002). 
Figure 1. The chemical composition of whole or full-fat and low-fat process cheeses. Adopted from (Mistry and Anderson, 1993)

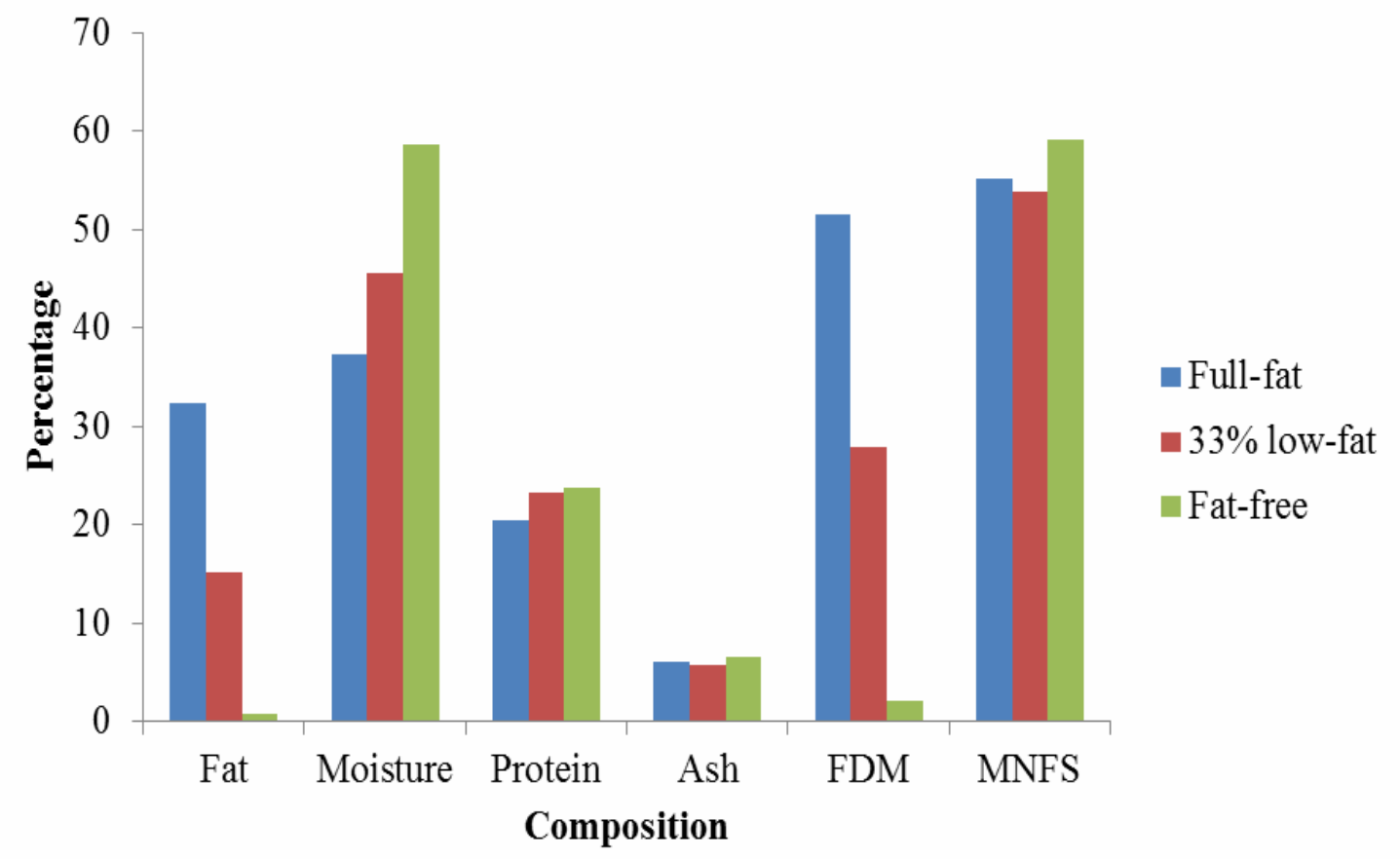

$\mathrm{FDM}=$ Fat in dry matter

MNFS $=$ Moisture in nonfat substance

\subsection{Sensory characteristics of low- fat PC}

Sensory studies conducted on commercial available full-fat PC spreads (21 \% fat), 60\% low-fat ( $8.4 \%$ fat), and low fat ( $3 \%$ fat) from the same manufacturer concluded that acid and bitter sensory attributes increased with decreased fat content (Muir et al., 1997). This study also observed increased graininess and stickiness of PC spreads with decreased fat content. The fat reduction also affected the spreadability and overall acceptability of the PC spreads. In order to decrease these perceivable sensory differences and to enhance the functional and sensory properties of low-fat or fat free PC, current approaches followed by many researchers involve manufacture of an acceptable quality fat free natural cheese that can be used as an ingredient in PC (Raval and Mistry, 1999; Mistry, 2001; Banks, 2004; Lee et al., 2006; Hassan et al., 2007; Metzger and Kapoor, 2007; Lucey, 2008) and use of fat replacers that can enhance the functional properties of low-fat or fat free PC (Jones, 1996; Drake et al., 1999).

\section{3. The functionality of low-fat PC}

A study conducted on low-fat PC that were made with ultrafiltered buttermilk containing low-fat natural cheese (Raval and Mistry, 1999). Low-fat Cheddar cheese was manufactured with a combination of ultrafiltered buttermilk and regular cheese milk. These natural cheeses were then utilized to produce three different low-fat PC (15\% fat) that differ in the level of emulsifying salt. 
These 50\% low-fat PC were compared with corresponding conventional 50\% low-fat PC made with regular low-fat natural cheese. The conclusions drawn from this investigation indicated that the ultra-filtered buttermilk Cheddar containing 50\% low-fat PC at all levels of emulsifying salt were less meltable, highly viscous, and had less free oil formation when compared to the control $50 \%$ low-fat PC made with regular low-fat natural cheese. As per their discussions, the high viscosity values of low-fat PC made with ultra-filtered buttermilk natural cheese were due to the stronger emulsion that was formed by the ultra-filtered buttermilk cheese incorporation. This study did not compare 50\% low-fat PC with whole or full-fat PC.

It has been announced that 35\% low-fat PC produced with low-fat Cheddar made from exopolysaccharide producing starter cultures had a smoother texture and more flowability relative to a $35 \%$ low-fat PC control that contained no Cheddar made from exopolysaccharideproducing starter culture (Hassan et al., 2007). This study concluded that $35 \%$ low-fat PC made with exopolysaccharide-producing starter culture had a similar sensory perception with the $35 \%$ low-fat PC control containing no exopolysaccharideproducing starter culture. Considering the improvements in the functional characteristics in the $35 \%$ low-fat PC produced with exopolysaccharideproducing starter culture without showing any sensory differences with the control 35\% low-fat PC that contained no Cheddar made from exopolysaccharide-producing starter cultures, this study concluded the use of Cheddar made from exopolysaccharide-producing starter cultures may be a solution to improve the functionality of low-fat PC. However, the comparison was only done between low-fat PC but not with the full-fat PC.

\section{4. Use of the fat replacers to de- velop low-fat $P C$}

Fat replacers are divided depending on the materials from which they are derived into carbohydratebased fat replacers (pectin, gums, starch, dextrin, vegetable fibers, and carrageenan), protein-based fat replacers (modified whey protein and soy protein), and fat-based fat replacers (mono and diglycerides, olestra, salatrim, and carpenin) (Napier, 1997).

Several different fat replacers have been shown to produce low-fat PC with improved functional characteristics (Davison et al., 1993; Mehnert and Prince, 1996; Drake et al., 1999; Swenson et al., 2000). A study on the physical and sensory properties of low-fat PC spread made using a hydrocolloid fat mimetics was completed (Brummel and Lee, 1990). In their study, different hydrocolloids (xanthan gum, guar gum, carrageenan, pectin, and zooglan) were added at different levels to manufacture two different low-fat PC spreads (40 and 50\% reduced). The control full-fat process spread contained $25 \%$ fat in this study. The texture and sensory characteristics of both the $40 \%$ and 50\% low-fat PC were evaluated and compared to the control. This study compared the texture of $40 \%$ low-fat PC spreads with pectin to full-fat $\mathrm{PC}$ and concluded that the 
firmness and melt values of the $40 \%$ low-fat PC spreads with pectin were low compared to the whole or full-fat PC spreads.

The effect of different hydrocolloids (guar gum, carrageenan, gelatin, locust bean gum), when used at the $2 \%$ level as fat replacers in fat-free PC, spread formulations was studied (Swenson et al., 2000). The full-fat PC spread was made with full-fat Cheddar whereas the fat-free PC spreads were made with skim milk cheese which did not have any hydrocolloids. These fat-free PC formulations were compared with the control full-fat PC spread for firmness, melt, and spreadability. The results concluded that full-fat PC spreads had lower firmness, higher melt, and higher spread-ability than the fat-free PC spread formulations. It has been reported that $50 \%$ low-fat PC containing lecithin had improved functional properties (elasticity, firmness, and cohesiveness) relative to a $50 \%$ low-fat control that contained no lecithin (Drake et al., 1999).

The effect of monoglycerides and diglycerides, when used as fat replacers in fat-free PC, was also studied (Lucey, 2008). His research study concluded the manufacture of fat-free PC with improved stretch, melt, and slice ability was possible. Earlier research studies on the use of fat substitutes also concluded that improvements in low-fat PC functional and sensory characteristics were possible (Kong-Chan et al., 1991; Mehnert and Prince, 1996). As an example, it has been reported that the employ of sucrose polyesters as fat substitutes in low-fat PC resulted in improved functional properties of low-fat PC (Mehnert and Prince, 1996).

\section{Cheddar Cheese}

Cheddar cheese which originated in the village of Cheddar in England is hard, bacteria ripened cheese, and has a cohesive, waxy texture with a generally bland flavor (Kosikowski and Mistry, 1977). The Code of Federal Regulations (CFR) (FDA, 2014) defines Cheddar cheese as "cheese made by the Cheddar process or by another procedure which produces a finished cheese having the same physical and chemical properties as the cheese produced by the Cheddar process and is made from cows' milk with or without the addition of color and with common salt, contains not more than $39 \%$ moisture and in the water free substance, contains not less than $50 \%$ milk fat and conforms to the provisions of Definitions and Standards of Identity for cheese and cheese products" (FDA, 2014).

\section{1. Low-fat Cheddar cheese}

During the past three decades, the production and consumption of low-fat food products have risen sharply. The cheese industry has developed low-fat Cheddar cheeses to cater to these demands and thereby expanded the market of cheese. However, low-fat Cheddar cheese has low shelf-life and sensory characteristics compared to full-fat Cheddar cheese (Olson and Johnson, 1990; Johnson and Chen, 1991; Simard, 1991).

The Code of Federal Regulations (CFR) (FDA, 2014) requires that in order to be called reduced-fat, fat reduced, lower fat or lower in fat, reduced in fat, less fat, the cheese must contain at least $25 \%$ less fat per 
reference amount customarily consumed. Products with serving size of $30 \mathrm{~g}$ or less may be classified as lowfat, low in fat, contains a small amount of fat, low source of fat, or little fat if they contain $3 \mathrm{~g}$ or less of fat per $50 \mathrm{~g}$ (FDA, 2014). Therefore, low-fat Cheddar cheese must contain $6 \%$ fat or less. Cheddar cheese may also be classified as light or less. To bear this claim the cheese must be compared to the reference food (fullfat Cheddar cheese). The label should claim the identity of the reference food and the percentage of the amount of fat decreased compared to the reference amount (FDA, 2014). In this review, the term low-fat is used to refer to cheeses lower in fat than full-fat cheese.

\section{2. Functional properties of low- fat Cheddar cheese}

The differences between full-fat and low-fat Cheddar cheeses are shown in Figure 2. The lower fat content in low-fat Cheddar cheese leads to several defects including poor texture, keeping quality, and flavor (LeRoux and Abbott, 1962; Simard, 1991). The two most important problems currently associated with lowfat Cheddar cheese are flavor and body and texture.

Figure 2. Composition of full-fat and low-fat Cheddar cheeses. Adopted from (Mistry and Anderson, 1993)

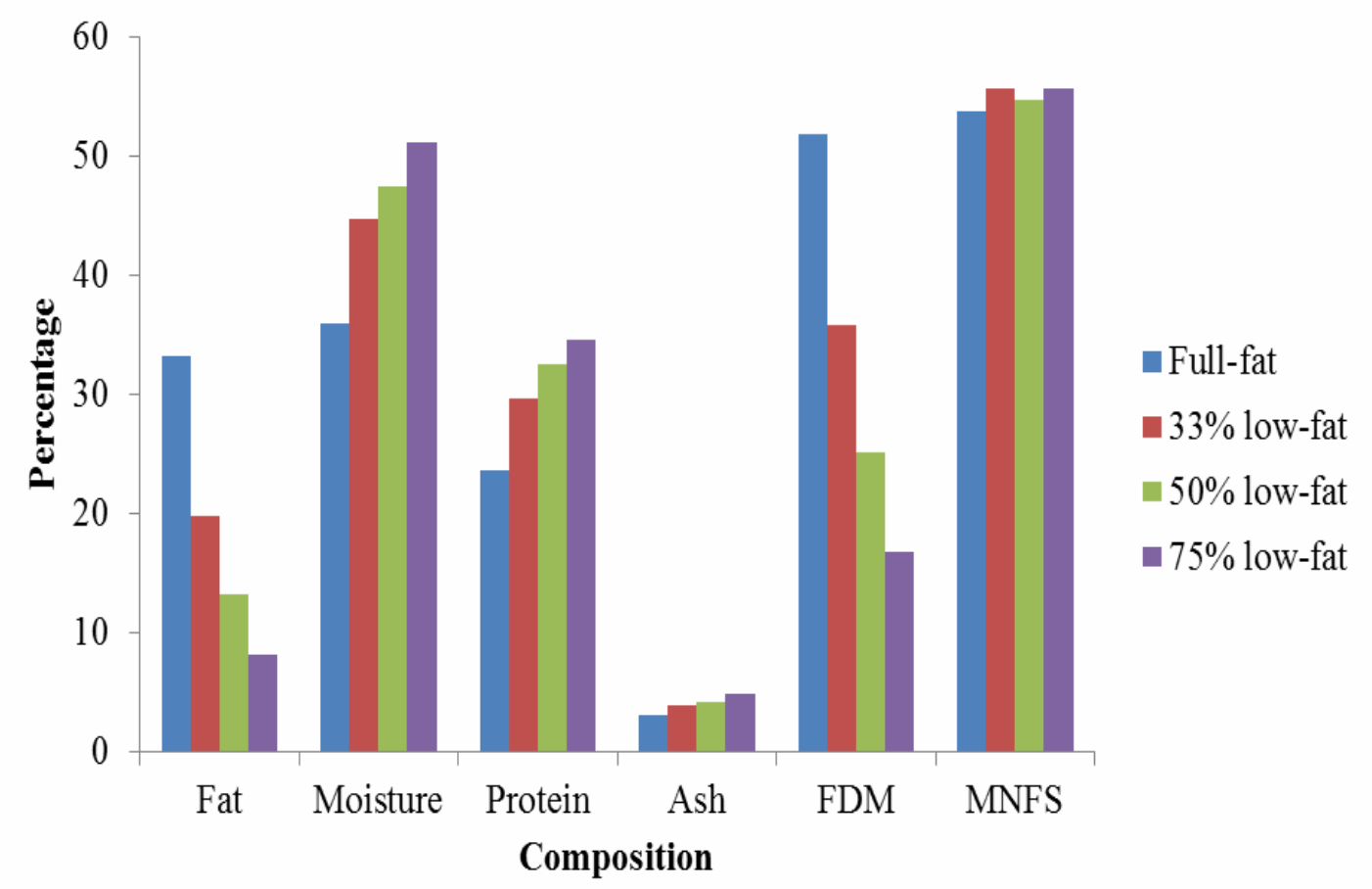

$\mathrm{FDM}=$ Fat in dry matter

MNFS= Moisture in nonfat substance

\section{3. Sensory characteristics of low-fat Cheddar cheese}

\section{3. 1. Flavor}

Milk fat plays a significant role in the flavor of cheese; it has a unique fatty acid profile including a large percentage of flavor-producing, short chain fatty acids (Olson and Johnson, 1990; Simard, 1991). The development of Cheddar flavor is not com- 
pletely understood; however, it is affected by several factors including $\mathrm{pH}$, salt to moisture ratio $(\mathrm{S} / \mathrm{M})$, milk composition, and bacterial growth. Optimum flavor development occurs in Cheddar cheese when the $\mathrm{pH}$ is between 5.0 and 5.2 after $24 \mathrm{~h}$ of manufacturing, with a range of 4 to $6 \%$ S/M (Lawrence et al., 1984). Low-fat Cheddar cheese typically has a $\mathrm{pH}$ of 5.2 to 5.4 after $24 \mathrm{~h}$ of manufacturing and a $\mathrm{S} / \mathrm{M}$ of 1.3 to $1.5 \%$ (Banks et al., 1989; Anderson et al., 1993). This altered environment in low-fat Cheddar cheese allows starter and nonstarter lactic acid bacteria (LAB) to grow to high numbers and lead to undesirable flavor defects, and poor keeping quality (Johnson and Chen, 1991; Simard, 1991).

Bitterness, the major flavor defect in low-fat Cheddar cheese, is caused by the proteolysis of casein and subsequent formation of bitter peptides during ripening. Proteolysis of casein is classified as primary or secondary (Grappin et al., 1985; Rank et al., 1985; Hammam et al., 2017, 2018). During primary proteolysis, chymosin hydrolyzes as casein and proteolytic enzymes, mainly from starter bacteria, degrade other caseins into peptides (Hammam et al., 2017; Hammam and Metzger, 2018). These peptides are further hydrolyzed to produce small peptides and amino acids by peptidases and aminopeptidases during secondary proteolysis (Olson et al., 1993; Pritchard and Coolbear, 1993; Hammam et al., 2017). Rapid primary proteolysis is associated with the development of bitter flavor in cheese (Grappin et al., 1985; Rank et al., 1985; Chen et al., 1992). The development of starters having lower primary proteolytic activity have helped improve flavor development in Cheddar cheese and may play an important role in improving the flavor of low-fat Cheddar cheese. Proteinase negative starter cultures, which lack the plasmid that encodes for the proteinase genes have low proteolytic activity (Richardson et al., 1983) and produce fewer incidences of bitter defects in full-fat Cheddar cheese (Emmons et al., 1962; Mills and Thomas, 1980). In addition to starter with low proteolytic activity, adjunct cultures such as Lactobacillus casei and Pediococcus spp. may improve flavor and flavor intensity of low-fat Cheddar cheese and decrease bitterness, through secondary proteolysis (Bhowmik et al., 1990; Simard, 1991).

Condensing milk prior to cheese making may also improve cheese flavor and decrease bitterness in low-fat Cheddar cheese. Condensing milk increases the mineral to moisture ratio of cheese which may inhibit excessive growth of $\mathrm{LAB}$ and prevent bitterness in low-fat Cheddar cheese (Anderson et al., 1993).

\section{3. 2. Body and Texture}

Cheddar cheese consists of a casein matrix containing embedded fat (Kimber et al., 1974; Jameson, 1990; Mistry and Anderson, 1993). The fat provides lubrication within the protein matrix and gives the cheese a "creamy" body, typically found in full-fat Cheddar cheese. When the fat content in Cheddar cheese is reduced, the casein plays a more dominating role in cheese structure. The optimum casein to fat ratio in milk for full-fat Cheddar cheese is 0.7 to 1 
(Kosikowski, 1977) and in milk for $40 \%$ low-fat Cheddar cheese it is 1.6:1 (Johnson, 1988). The increased casein content results a firm and rubbery body and texture in the cheese (Rogers et al., 2010; Farkye and Guinee, 2017). These defects are partly overcome in low-fat Cheddar cheese by escalating cheese moisture content (Banks et al., 1989; Johnson and Chen, 1991; Simard, 1991; Anderson et al., 1993).

The moisture in fat-free cheese ratio (MFFC) in low-fat cheeses is therefore generally similar to that in whole or full-fat cheese (Mistry and Anderson, 1993). This approach only marginally improves the body and texture of low-fat Cheddar cheese (Banks et al., 1989). Adjunct cultures which increase secondary proteolysis may soften cheese body (Banks et al., 1989; Bhowmik et al., 1990; Hammam et al., 2018) but, the cheese tends to become weak and pasty during ripening. Body and texture defects, therefore, remain prevalent in low-fat cheeses.

\section{4. Modifications of cheesemak- ing procedure}

Several modifications are made in the Cheddar cheese make the procedure to obtain a low-fat Cheddar cheese (LeRoux and Abbott, 1962; Walstra and Oortwijn, 1975). Traditional Cheddar cheese manufacturing procedures used with low-fat milk produce cheese with an extremely hard body (LeRoux and Abbott, 1962). The modifications in the traditional procedure are therefore primarily for the purpose of increasing cheese moisture. The cooking temperature is reduced from $39^{\circ} \mathrm{C}$ to 34 to $37^{\circ} \mathrm{C}$ and the cooking time is de- creased by 15 to $30 \mathrm{~min}$. These changes lessen the amount of whey expelled from the curd (Banks et al., 1989; Johnson and Chen, 1991; Simard, 1991). The $\mathrm{pH}$ at mill is between 5.5 and 5.7 for low-fat Cheddar cheese (Johnson and Chen, 1991), whereas full-fat Cheddar is milled at pH 5.2 to 5.4 (Lawrence et al., 1984). This modification also limits whey expulsion from the curd (Johnson and Chen, 1991). An additional, but controversial method to increase moisture is washing the curd after cooking. Washing reduces the lactose content and helps control pH (Johnson and Chen, 1991; Simard, 1991). However, washing decreases flavor intensity and promotes excessive bacterial growth by decreasing mineral content in the cheese (Metzger, 1994).

\section{Conclusion}

The term "low-fat cheese" varies depending on the type of cheese and country. Cheese with low fat than the full-fat version is considered as low-fat cheese. Demand for low-fat cheese has increased over the past two decades. Fat has a major contribution in the flavor, body and texture of the cheese. Several low-fat cheeses are characterized by low flavor, weak body texture, and low functionality. The dairy industry's response to health-conscious consumers and government health authorities is to provide low-fat cheeses with low additives to consumers. The main challenge for cheese makers is manufacturing low-fat cheeses with typical texture and flavor characteristics similar to the whole or full-fat cheeses. Approaches utilized for low-fat 
cheese could enhance the texture but not the cheese flavor and vice versa.

\section{References}

Anderson, D.L., Mistry, V. V, Brandsma, R.L., and Baldwin, K.A. (1993). Reduced fat Cheddar cheese from condensed milk. 1. Manufacture, composition, and ripening. J. Dairy Sci. 76: 28322844.

Banks, J.M. (2004). The technology of low-fat cheese manufacture. Int. J. Dairy Technol. 57: 199-207.

Banks, J.M., Brechany, E.Y., and Christie, W.W. (1989). The production of low fat Cheddar-type cheese. Int. J. Dairy Technol. 42: 6-9.

Bellisle, F., Rolland-Cachera, M., Deheeger, M., Preziosi, P., and Hercberg, S. (1994). Intake of 'low-fat'foods in a representative sample of the Paris area: anthropometric, nutritional and socio-demographic correlates. J. Hum. Nutr. Diet. 7: 335-346.

Berger, W., Klostermeyer, H., Merkenich, K., and Uhlmann, G. (1998). Processed cheese manufacture, a JOHA guide. BK Giulini Chemie GmbH Co. OHG, Ladenburg, Ger.

Bhowmik, T., Riesterer, R., Boekel, M. Van, and Marth, E.H. (1990). Characteristics of low-fat Cheddar cheese made with added Micrococcus or Pediococcus species. Milchwissenschaft 45: 230-235.

Brown, N.D. (1989). Manufacture of Cornhusker cheese with reduced fat content. Cult. Dairy Prod. J. 24: 23-25.

Brummel, S.E., and Lee, K. (1990). Soluble hydrocolloids enable fat reduction in process cheese spreads. J. Food Sci. 55: 12901292.

Caric, M., Gantar, M., and Kalab, M.
(1985). Effects of emulsifying agents on the microstructure and other characteristics of process cheese-A review. Food Struct. 4: 13.

Chen, C.M., Johnson, M.E., and Olson, N.F. (1991). Relantionship between manufacturing practices and quality of reduced fat Cheddar cheese. J. Dairy Sci 74: 95.

Chen, C.M., Macedo, A.C., Johnson, M.E., and Olson, N.F. (1992). Analysis of four starter cultures in the ripening of reduced fat Cheddar cheese. In American Dairy Science Association, (J. Dairy Sci), p 75.

Davison, B.C., Schwimmer, W.H., Prostko, L.J., Hamann, A.C., Buliga, G.S., Heth, A.A., Jackson, L.K., Kerwin, P.J., Miller, M.S., Pechak, D.G. (1993). Low fat processed cheese product having fat-mimetic properties and method of making same. U.S. Patent No. 5,215,778. Washington, DC: U.S. Patent and Trademark Office.

Drake, M.A., Truong, V.D., and Daubert, C.R. (1999). Rheological and sensory properties of reducedfat processed cheeses containing lecithin. J. Food Sci. 64: 744-747.

Emmons, D.B., McGugan, W.A., Elliott, J.A., and Morse, P.M. (1962). Effect of strain of starter culture and of manufacturing procedure on bitterness and protein breakdown in Cheddar cheese. J. Dairy Sci. 45: 332-342.

Ennis, M.P., O'Sullivan, M.M., and Mulvihill, D.M. (1998). The hydration behaviour of rennet caseins in calcium chelating salt solution as determined using a rheological approach. Food Hydrocoll. 12: 451-457.

Farkye, N.Y., and Guinee, T.P. (2017). Low-Fat and Low-Sodium Cheeses. In Cheese, (Elsevier), pp 
699-714.

FDA, (2014). Code of Federal Regulations Title 21-Food and Drugs. Dep. Heal. Hum. Serv. (Ed.). US Food Drug Adm.

Gould, B.W., Cornick, J., and Cox, T. (1994). Consumer Demand for New Reduced-fat Foods: An Analysis of Cheese Expenditures. Can. J. Agric. Econ. Can. d'agroeconomie 42: 367-380.

Grappin, R., Rank, T.C., and Olson, Nf. (1985). Primary proteolysis of cheese proteins during ripening. A review. J. Dairy Sci. 68: 531-540.

Gupta, S.K., Karahadian, C., and Lindsay, R.C. (1984). Effect of emulsifier salts on textural and flavor properties of processed cheeses. J. Dairy Sci. 67: 764-778.

Gwartney, E.A., Foegeding, E.A., and Larick, D.K. (2002). The texture of commercial full-fat and reducedfat cheese. J. Food Sci. 67: 812816.

Hammam, A.R.A., and Metzger, L.E. (2018). Production and storage stability of liquid micellar casein concentrate. J. Dairy Sci. 101: 8.

Hammam, A.R.A., Tammam, A.A., and El-Rahim, A.M.A. (2018). Effect of different heat treatments on the characteristics of Ras cheese during ripening. Egypt. J. Dairy Sci. 46: 111-119.

Hammam, A.R.A., Tammam, A.A., Elderwy, Y.M.A., and Hassan, A.I. (2017). Functional Peptides in Milk Whey: An Overview. Assiut J. Agric. Sci. 48: 77-91.

Hassan, A.N., Awad, S., and Mistry, V. $\mathrm{V}$ (2007). Reduced fat process cheese made from young reduced fat cheddar cheese manufactured with exopolysaccharide-producing cultures. J. Dairy Sci. 90: 36043612.

Jameson, G.W. (1990). Cheese with less fat. Aust. J. Dairy Technol. 45: 93-
98.

Johnson, M.E. (1988). High-fat and lowfat cheese. Standardization and compositional interrelationships. In Proc. Ctr. Dairy Res., (Univ. Wisconsin, Madison, WI), p 113.

Johnson, M.E., and Chen, C. (1991). Making quality reduced-fat cheese. In Low-Fat Cheddar Seminar, p.

Johnson, M.E., Kapoor, R., McMahon, D.J., McCoy, D.R., and Narasimmon, R.G. (2009). Reduction of sodium and fat levels in natural and processed cheeses: Scientific and technological aspects. Compr. Rev. Food Sci. Food Saf. 8: 252-268.

Jones, S.A. (1996). Issues in fat replacement. Handb. Fat Replace. 3-26.

Kapoor, R., and Metzger, L.E. (2008). Process cheese: Scientific and technological aspects-A review. Compr. Rev. Food Sci. Food Saf. 7: 194-214.

Kimber, A.M., Brooker, B.E., Hobbs, D.G., and Prentice, J.H. (1974). Electron microscope studies of the development of structure in Cheddar cheese. J. Dairy Res. 41: 389-396.

Kong-Chan, J.L.Y., Hellyer, J.A., and Tafuri, M.W. (1991). Simulated cheese products with reduced animal fat and calories.

Kosikowski, F. V (1977). Cheese and fermented milk foods. Edwards Brothers. Inc., Ann Arbor, MI 48104:.

Kosikowski, F. V, and Mistry, V. V (1977). Cheese and fermented milk foods (Edwards Bros.).

Lawrence, R.C., Heap, H.A., and Gilles, J. (1984). A controlled approach to cheese technology. J. Dairy Sci. 67: 1632-1645.

Lee, S.K., Buwalda, R.J., Euston, S.R., Foegeding, E.A., and McKenna, A.B. (2003). Changes in the 
rheology and microstructure of processed cheese during cooking. LWT-Food Sci. Technol. 36: 339345.

Lee, W., Clark, S., and Swanson, B.G. (2006). Low fat process cheese food containing ultrahigh pressuretreated whey protein. J. Food Process. Preserv. 30: 164-179.

LeRoux, G.D., and Abbott, C.W. (1962). South Africa's new low-fat cheese. Dairy Eng. 79: 270.

Lucey, J.A. (2008). Advances in nonfat/lowfat process cheese for melting and ingredient use. J. Dairy Sci. 91: 153.

Marchesseau, S., and Cuq, J.L. (1995). Water-holding capacity and characterization of protein interactions in processed cheese. J. Dairy Res. 62: 479-489.

McMahon, D.J. (2010). Issues with lower fat and lower salt cheeses. Aust. J. Dairy Technol. 65: 200.

Mehnert, D.W., and Prince, S. (1996). Methods and compositions for fat free process cheese.

Merrill, R.K., Oberg, C.J., and McMahon, D.J. (1994). A method for manufacturing reduced fat Mozzarella cheese. J. Dairy Sci. 77: $1783-1789$.

Metzger, L.E. (1994). Application of cream homogenization in the manufacture of reduced fat cheddar cheese.

Metzger, L.E., and Kapoor, R. (2007). Novel approach for producing process cheese with reduced fat and reduced sodium content.

Metzger, L.E., and Mistry, V. V (1994). A new approach using homogenization of cream in the manufacture of reduced fat Cheddar cheese. 1. Manufacture, composition, and yield. J. Dairy Sci. 77: 3506-3515.

Meyer, A. (1973). Processed cheese manufacture. (Food Trade Press
Ltd. London, UK).

Mills, O.E., and Thomas, T.D. (1980). Bitterness development in Cheddar cheese: effect of the level of starter proteinase. New Zeal. J. Dairy Sci. Technol. 15: 131-141.

Mistry, V.V. (1995). Improving the sensory characteristics of reducedfat cheese. In Chemistry of Structure-Function Relationships in Cheese, (Springer), pp 371-382.

Mistry, V.V. (2001). Low fat cheese technology. Int. Dairy J. 11: 413422.

Mistry, V.V. and Anderson, D.L. (1993). Composition and microstructure of commercial full-fat and low-fat cheeses. Food Struct. 12: 13.

Muir, D.D., Williams, S.A.R., Tamime, A.Y., and Shenana, M.E. (1997). Comparison of the sensory profiles of regular and reduced-fat commercial processed cheese spreads. Int. J. Food Sci. Technol. 32: 279-287.

Napier, K. (1997). Fat replacers: The cutting edge of cutting calories (Am Cncl on Science, Health).

Nauth, K.R., and Hayashi, D.K. (1995). Method for manufacture of low fat pasta filata cheese. Washington, DC: U.S. Patent and Trademark Office.

Olson, N.F., and Johnson, M.E. (1990). Light cheese products: characteristics and economics. Food Technol. 44: 93.

Olson, N.F., Mcsweeney, P.L.H., and Fox, P.F. (1993). Specificity of proteinases on casein and implications for cheese maturation. In Ctr. for Dairy Res. Annual Rep, p 92.

Pritchard, G.G., and Coolbear, T. (1993). The physiology and biochemistry of the proteolytic system in lactic acid bacteria. FEMS Microbiol. Rev. 12: 179-206.

Rank, T.C., Grappin, R., and Olson, N.F. 
(1985). Secondary proteolysis of cheese during ripening: a review. J. Dairy Sci. 68: 801-805.

Rashidinejad, A., Birch, E.J., SunWaterhouse, D., and Everett, D.W. (2013). Effects of catechin on the phenolic content and antioxidant properties of low-fat cheese. Int. J. Food Sci. Technol. 48: 2448-2455.

Raval, D.M., and Mistry, V. V (1999). Application of ultrafiltered sweet buttermilk in the manufacture of reduced fat process cheese. J. Dairy Sci. 82: 2334-2343.

Richardson, G.H., Ernstrom, C.A., Kim, J.M., and Daly, C. (1983). Proteinase negative variants of Streptococcus cremoris for cheese starters. J. Dairy Sci. 66: 22782286.

Rogers, N.R., McMahon, D.J., Daubert, C.R., Berry, T.K., and Foegeding, E.A. (2010). Rheological properties and microstructure of Cheddar cheese made with different fat contents. J. Dairy Sci. 93: 4565-4576.

Ryhänen, E.-L., Pihlanto-Leppälä, A., and Pahkala, E. (2001). A new type of ripened, low-fat cheese with bioactive properties. Int. Dairy J. 11: 441-447.

Sánchez-Macías, D., Fresno, M., Moreno-Indias, I., Castro, N., Morales-delaNuez, A., Álvarez, S., et al. (2010). Physicochemical analysis of full-fat, reduced-fat, and low-fat artisan-style goat cheese. J. Dairy Sci. 93: 39503956.

Simard, R.E. (1991). Evaluation of low fat cheese problems. In Proceedings CDR Cheese Research and Technology Conference (37-39) Madison University of Wisconsin, $\mathrm{p}$.

Solheim, R., and Lawless, H.T. (1996). Consumer purchase probability affected by attitude towards lowfat foods, liking, private body consciousness and information on fat and price. Food Qual. Prefer. 7: 137-143.

Swenson, B.J., Wendorff, W.L., and Lindsay, R.C. (2000). Effects of ingredients on the functionality of fat-free process cheese spreads. J. Food Sci. 65: 822-825.

Thomas, M.A. (1973). The manufacture of processed cheese. Scientific principles. Manuf. Process. Cheese. Sci. Princ.

Wadhwani, R., and McMahon, D.J. (2012). Color of low-fat cheese influences flavor perception and consumer liking. J. Dairy Sci. 95: 2336-2346.

Walstra, P., and Oortwijn, H. (1975). Effect of globule size distribution in milk. Netherlands Milk Dairy J. 29: 279. 


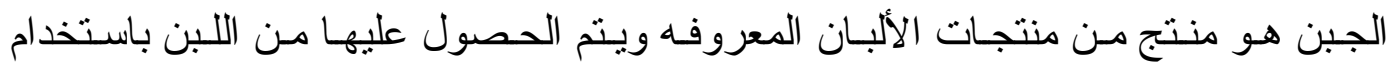

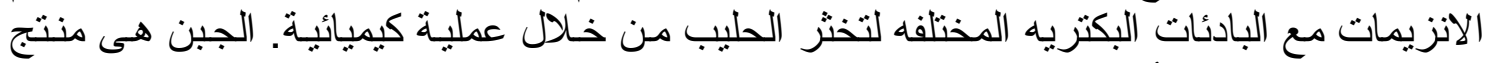

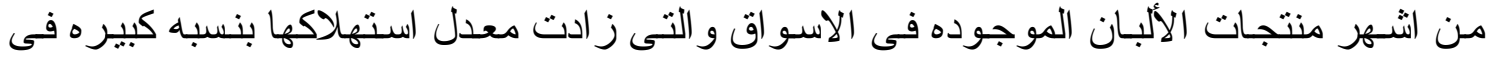

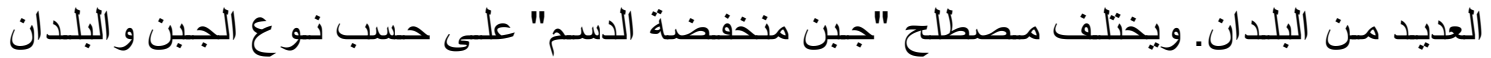

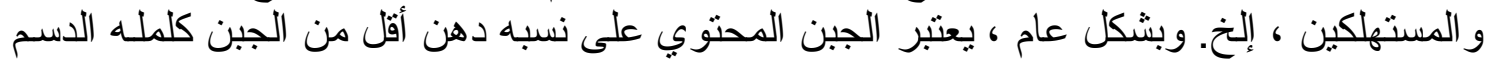

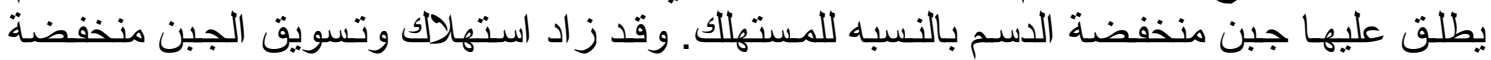

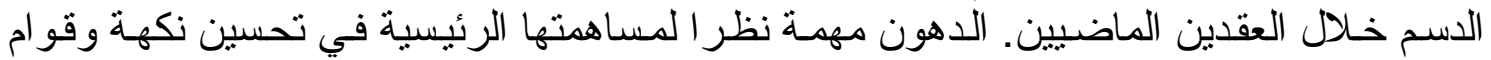

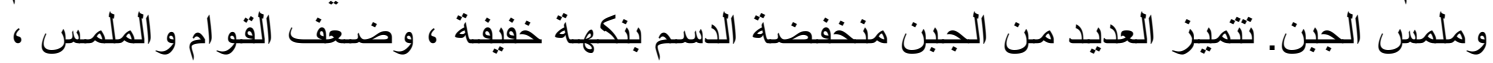

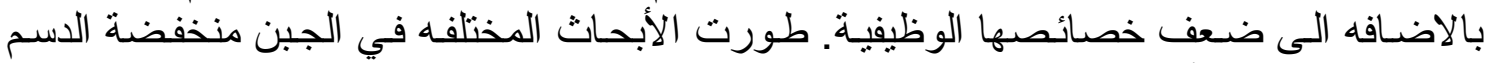

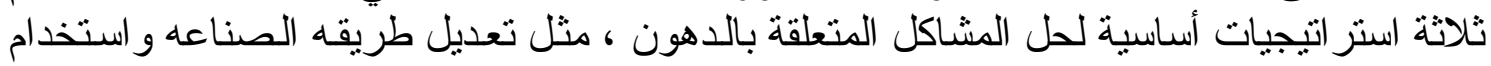

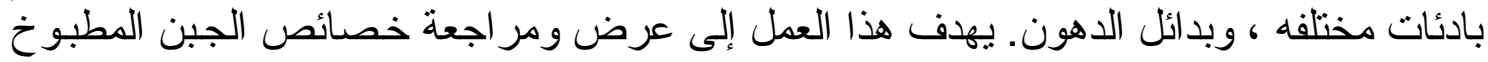

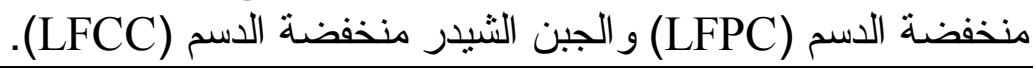

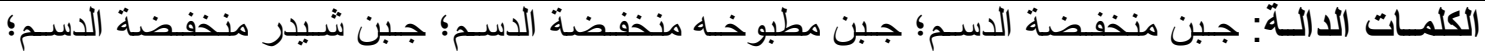
الخصائص الحسيه؛ الخصائص الوظيفية 